\title{
Avaliação da Eficiência de Três Métodos Utilizados como Controle da Qualidade dos Exames Citopatológicos Cervicais Classificados como Negativos no Escrutínio de Rotina
}

Evaluation the Efficiency of Three Methods of Internal Quality Control of the Cytopathology Classified as Negative During Routine Screening

\author{
Edna Joana Cláudio Manrique', Rita Goreti Amaral²
}

\begin{abstract}
Resumo
O exame citopatológico é o método mais utilizado para prevenção e detecção precoce de câncer cervical. Mas os resultados falso-negativos ainda são um dos grandes problemas dos laboratórios de citopatologia. $\mathrm{O}$ método de revisão aleatória de $10 \%$ dos esfregaços interpretados previamente como negativos tem sido o mais utilizado como controle interno da qualidade, no entanto, com pouca eficiência. Assim, o objetivo deste estudo foi comparar a eficiência da revisão rápida de $100 \%$, revisão de esfregaços selecionados com base em critérios clínicos e revisão aleatória de $10 \%$ como métodos de controle interno da qualidade dos esfregaços cervicais negativos no escrutínio de rotina. Teve como base a população feminina usuária do Sistema Único de Saúde de Goiânia-GO, que se submeteu ao exame citopatológico realizado no Laboratório de Análises Clínicas Rômulo Rocha da Faculdade de Farmácia da Universidade Federal de Goiás. Os 5.530 esfregaços classificados como negativos no escrutínio de rotina foram submetidos ao método de revisão rápida de $100 \%$, em seguida, foram selecionados os esfregaços com base em critérios clínicos e, por último, $10 \%$ do total de esfregaços negativos e submetidos aos respectivos métodos de revisões. Todas as etapas foram às cegas e os resultados classificados de acordo com o Sistema de Bethesda. A revisão rápida de 100\% identificou 141 esfregaços suspeitos, desses, 84 (59,6\%) foram considerados alterados pelo diagnóstico final, dos quais $36(25,5 \%)$ foram classificados como células escamosas atípicas de significado indeterminado (ASC-US), cinco (3,5\%) como células escamosas atípicas, não podendo excluir lesão de alto grau (ASC-H), 34 (24,1\%) como lesão intra-epitelial escamosa de baixo grau (LSIL), seis $(4,3 \%)$ como lesão intra-epitelial de alto grau (HSIL) e três $(2,1 \%)$ células glandulares atípicas (AGC). Dos 1.279 esfregaços revisados com base em critérios clínicos, 19 (79,2\%) foram confirmados como alterados pelo diagnóstico final, sendo nove (47,3\%) classificados como ASC-US, um (5,3\%) ASC-H, oito (42,1\%) LSIL e um (5,3\%) HSIL. Dos 560 esfregaços analisados pela revisão de $10 \%$, seis $(46,2 \%)$ foram confirmados pelo diagnóstico final, sendo quatro $(30,8 \%)$ classificados como ASC-US, um (7,7\%) LSIL e um (7,7\%) HSIL. Portanto a revisão rápida de $100 \%$ é um método de controle interno da qualidade mais eficiente na detecção de resultados falso-negativos dos exames citopatológicos, do que a revisão com base em critérios clínicos e revisão aleatória de $10 \%$.
\end{abstract}

\footnotetext{
${ }^{1}$ Autora

${ }^{2}$ Orientadora

Dissertação apresentada ao Programa de Pós-graduação em Ciências da Saúde da Universidade Federal de Goiás para obtenção do título de Mestre em Ciências da Saúde - Goiânia (GO), 2007

Área de concentração: Patologia, Clínica e Tratamento das Doenças Humanas

Agência de fomento: Conselho Nacional de Desenvolvimento Científico e Tecnológico - CNPq

Endereço para correspondência: Edna Joana Cláudio Manrique. Rua 242, Qd. 42-A, Lt. 13 - Setor Leste Universitário - Goiânia (GO), Brasil.

CEP: 74603-190. E-mail: ednamanrique@gmail.com
} 